\title{
RECRUTAMENTO E SELEÇÃO: UM CONTRASTE ENTRE O NOVO E O TRADICIONAL
}

\section{ARTIGO DE REVISÃO}

NETO, Anisio de Queiroz Monteiro ${ }^{1}$

SCATOLIN, Henrique Guilherme ${ }^{2}$

NETO, Anisio de Queiroz Monteiro. SCATOLIN, Henrique Guilherme. Recrutamento e seleção: Um contraste entre o novo e o tradicional. Revista Científica Multidisciplinar Núcleo do Conhecimento. Ano 05, Ed. 03, Vol. 12, pp. 33-48. Março de 2020. ISSN: 2448-0959, Link de acesso: https://www.nucleodoconhecimento.com.br/psicologia/novo-e-o-tradicional

\section{RESUMO}

Atualmente, com o avanço da tecnologia, não seria incomum ver um progresso no setor de Recursos Humanos, mais especificamente na questão de seleção e recrutamento. Dentre os avanços observados nessa área, destaca-se o recrutamento online ou e-recrutamento. A seleção online pode trazer várias vantagens para as organizações que as realizam, mas até que ponto é fidedigna à seleção tradicional? Assim, o presente trabalho, utilizando uma metodologia de revisão bibliográfica, tem como objetivo apresentar uma comparação entre três métodos de recrutamento e seleção, quais sejam, o tradicional, por competências e o online, e mostrar vantagens e desvantagens para as empresas ao escolherem um deles. Foi realizada uma comparação entre a seleção tradicional, a seleção por competências e a seleção online e o resultado obtido evidencia que a aplicabilidade dos três métodos é válida

${ }^{1}$ Graduado em Psicologia pelo Centro Universitário das Faculdades Associadas de Ensino (2016). Pós-Graduado em Psicologia Organizacional e do Trabalho em FHOUNIARARAS.

${ }^{2}$ Doutor em Psicologia. 
nos dias de hoje, entretanto, há pontos fortes e fracos. Verificou-se, ainda, que a seleção online expandiu a visão a despeito do recrutamento e da captação de novos de talentos, inclusive, com melhor custo e benefício para as empresas. Conclui-se que a tecnologia se tornou um importante recurso para as organizações selecionarem novos talentos, uma vez que as vagas de emprego têm mais visibilidade a seus candidatos e resposta mais rápida, e propiciou um diálogo mais aberto entre candidato e empresa, além de custos mais baixos quando comparada a outros métodos de recrutamento e seleção.

Palavras-chave: Recrutamento, seleção, recrutamento online, seleção online.

\section{INTRODUÇÃO}

A contínua evolução da tecnologia mantém fielmente o seu objetivo desde o início da Revolução Industrial, no século XVIII, qual seja, o de agilizar as tarefas humanas ou até de substituir a mão de obra por uma máquina. Nesse ínterim, observa-se, na contemporaneidade, a presença cada vez mais maciça da automação dos serviços, possibilitada pelo aperfeiçoamento de plataformas digitais. Logo, é comum depararse com sites de recrutamento e seleção online, por meio dos quais o candidato preenche o seu currículo em formulários padronizados e, após esse procedimento, encontra as vagas disponibilizadas por diversas empresas, nas mais variadas funções existentes em uma organização.

Pedroso (2016) afirma que, em um contexto mais recente, fruto da crise financeira e das crescentes taxas de desemprego, houve uma mudança no paradigma da procura de emprego, já que muitos candidatos se afastaram dos canais tradicionais de seleção (agências locais, jornais, rádio, televisão) e migraram para meios alternativos de busca de novas oportunidades.

Da perspectiva do gestor de Recursos Humanos $(\mathrm{RH})$, o recrutamento e a seleção online - ou e-recrutamento - possibilitam contar com indicações e pesquisas online (D' ÁVILA et. al. 2010). Nesse contexto, D' Ávila et al. (2010) apontam que as formas tradicionais desse processo tornaram-se rapidamente obsoletas, evidenciando-se a 
necessidade de adaptação às novas técnicas e tecnologias, principalmente, à internet, a qual permite não só preencher vagas disponíveis, mas também localizar "candidatos passivos", isto é, profissionais que não estão à procura de um posto de trabalho. Tais páginas fornecem os cadastros de currículos para futuras vagas - até uma rede web exclusiva e informal de relacionamentos - para profissionais procurarem qualquer tipo de vaga em diversas empresas.

Para Moura (2014), o recrutamento tradicional recorre a vários processos, classificados, atualmente, como demorados e não tão eficientes. Por outro lado, o método online, sustentado por aplicações tecnológicas, aperfeiçoa o processo de seleção ao nível da interação e da automatização, visto que recorre à utilização da internet para encontrar, atrair, avaliar, entrevistar e contratar novos funcionários para uma organização de forma mais global e, praticamente, em tempo real.

A finalidade do e-recrutamento, portanto, é tornar os processos que compõem a seleção mais eficientes e eficazes, uma vez que permite, concomitantemente, reduzir a burocracia no processo de seleção e atingir um maior número de candidatos, facilitando, assim, o recrutamento e a seleção (MOURA, 2014).

Nesse sentido, a interação que o e-recrutamento possibilita a candidatos e organização permite oferecer respostas para algumas necessidades identificadas em outras formas de recrutamento e seleção, sobretudo, na fase inicial de publicação dos anúncios de oportunidades de emprego.

A crescente utilização da internet e a proliferação das redes sociais online fazem com que exista uma mudança real na forma como as organizações captam os candidatos, passando a utilizar as ferramentas virtuais com maior frequência (FERREIRA, 2016).

Nesse contexto, Costa (2012) destaca que o recrutamento e a seleção online representam uma das mais atuais, úteis e dinâmicas aplicações de gestão de pessoas. Se, por um lado, os indivíduos recorrem, cada vez mais, à internet para procurar novas oportunidades profissionais, de outro, as organizações valem-se do mesmo recurso para focar na seleção e na contratação de pessoas certas para o lugar 
certo, o que implica minimizar o tempo empreendido entre essas duas etapas. Devido a isso, hoje em dia, as empresas mais dinâmicas e orgânicas deixam para trás as mais antigas.

Deve-se ressaltar, também, a importância do e-recrutamento para as organizações no sentido de estas terem a seu dispor um universo de candidatos consideravelmente maior a que teriam acesso caso optassem pelas metodologias tradicionais de seleção e recrutamento. Ademais, destaca-se como vantagem a maior agilidade no recrutamento de pessoal e redução de custos, os quais são consideravelmente menores quando comparados ao processo tradicional, pois se trata de quantas pessoas visualizarão a vaga anunciada e interessar-se-ão pela mesma. $O$ anúncio de uma vaga pode ser publicado por uma organização e permanecer apenas um dia na internet, mas o número de pessoas que a visualizarão será bem maior que qualquer outro tipo de método de seleção (ALVES, 2002).

Nesse contexto, o que chama a atenção das empresas no processo de seleção online é a facilidade para selecionar os diversos candidatos de forma automática, atribuindo características e requisitos específicos, para enriquecer e dar maior visualização aos anúncios de empregos online. Para os candidatos, a grande vantagem é a facilidade de distribuir informação do seu percurso profissional, das experiências e dos objetivos de carreira, de forma permanente e global, com a ajuda de sites específicos para novas vagas em empresas (ALVES, 2002).

Nessa conjuntura, Viera (2010) diz que sites específicos para recrutamento e seleção online são dedicados a todas as carreiras e sustentados tanto pelas pessoas que se cadastram e registram seus currículos como pelas empresas que, por meio de um motor de buscas eficaz, obtêm currículos de candidatos com os requisitos desejáveis para as vagas pretendidas.

Em vista da discussão proposta pelos autores supracitados, este trabalho lança a seguinte problemática: a partir dos métodos de seleção já existentes, como a seleção online é relevante para as empresas? A hipótese apresentada é a de que, considerando os fatores positivos da seleção online, tais aspectos contribuam com a 
redução de tempo, custo e com a facilidade de divulgação de vagas e captação de candidatos para as empresas. Por fim, ressaltamos a relevância desta investigação em razão de haver parâmetros científicos para comparar e analisar a seleção online com processos já existentes e a escassa pesquisa sobre o tema no Brasil.

\section{METODOLOGIA}

A metodologia utilizada no presente trabalho é a revisão bibliográfica. Para Souza et al. (2010), a pesquisa bibliográfica é uma das melhores formas de iniciar um estudo, buscando semelhanças e diferenças entre artigos levantados nos documentos de referência. Assim sendo, a compilação de informações em meios eletrônicos (computadores, notebook e tablets) é um grande avanço para os pesquisadores, democratizando o acesso e proporcionando atualizações frequentes. O propósito geral de uma revisão bibliográfica, por conseguinte, é reunir conhecimentos sobre um tópico, ajudando nas fundações de um estudo significativo.

Por um lado, a revisão bibliográfica não utiliza critérios explícitos ou sistemáticos para busca e análise crítica da literatura, de outro, não precisa esgotar as fontes de informações ou aplicar meios de busca refinada ou exaustiva, porquanto a seleção das fontes de pesquisa e a interpretação das informações podem estar sujeitas à subjetividade dos autores. Todavia, é adequada para a fundamentação teórica de artigos, dissertações e teses, entre outros textos acadêmicos. A busca das fontes não é predeterminada e específica, sendo frequentemente menos abrangente (CORDEIRO et. al. 2007).

Este trabalho realizou uma pesquisa de revisão bibliográfica nacional na base de dados SciElo e Google Acadêmico. Utilizou como descritores de inclusão as palavras: seleção tradicional, seleção por competências e seleção online, e como descritores de exclusão: artigos não relacionados ao tema, títulos, artigos com o ano de publicação inferior a 2010, resultados não claros, autores que não falam sobre o tema. Foram excluídos dissertações e artigos que não se relacionam com o tema recrutamento, seleção e seleção online. Já os critérios de exclusão para os artigos 
relacionados ao tema foram publicações em anos inferiores a 2010 e em revistas, jornais, blogs e monografias de caráter não científico.

$\mathrm{Na}$ busca realizada por artigos a partir de 2010, foram encontrados artigos, livros e teses relacionadas ao tema. Em maior quantidade, foram encontradas dissertações de mestrado e artigos acadêmicos nas áreas da Administração, Psicologia e Gestão de Pessoas. Foram encontrados sessenta e quatro artigos no total, sendo, conforme o critério de descritores de inclusão: os resultados dos artigos encontrados, a data, os resumos, títulos e autores. Ao todo, dezessete deles foram utilizados neste trabalho[3].

\section{FUNDAMENTAÇÃO TEÓRICA}

Neste tópico, será apresentada uma discussão que irá mensurar a seleção clássica, a seleção por competências e a seleção online. Essa mensuração será fundamental para os próximos tópicos que serão desenvolvidos nesta pesquisa.

Ariera e Guimarães (2005) apontam que todo processo de seleção deve ter um planejamento estratégico, com objetivos a longo prazo, para eventuais ocorrências que não venham a prejudicar o bom andamento da empresa, principalmente, se os substitutos não forem eficazes. A seleção é o processo pelo qual será feita a escolha dos candidatos que possuam o perfil necessário para ocupar o cargo e, se realizado de forma correta, garante a entrada de pessoas com um potencial elevado na organização.

Neste contexto, Engenneni (2009 apud Antunes 2016) observa que, nesta etapa, podem ser utilizados métodos da seleção tradicional para avaliar e comparar as qualificações dos candidatos. Os métodos são:

- Teste: Antunes (2016) afirma que se trata de um conjunto de exercícios cuja finalidade é avaliar aspectos necessários para o cargo. Os testes servem para complementar as informações importantes que não são transmitidas pelo currículo. Alguns tipos de testes são: de personalidade, aprendizado, físicos, 
biológicos e testes psicológicos. Os testes psicológicos são utilizados desde o início da seleção científica de Taylor.

- Entrevista: o mesmo autor diz que é o método mais utilizado, pois permite o contato direto com o candidato. Para a entrevista, é preciso estar preparado para diversos tipos de respostas e reações dos candidatos e ser observador, a fim de avaliar cada detalhe e cada resposta. Para o candidato, exige preparação psicológica para responder a questões profissionais e pessoais, estar no local na hora combinada, de maneira apresentável, sendo imprescindível ser totalmente honesto em suas respostas.

- Dinâmica de grupo: ainda o mesmo autor diz que, nesta fase, inicialmente, procura-se promover um clima de integração e harmonia entre os candidatos, estimulando-os a uma participação ativa, incentivando a vivência de situações semelhantes às atividades que exercerão em suas funções, com o objetivo de observar atitudes, postura, linguajar, relacionamento interpessoal, traços de personalidade, interesses e comprometimento com uma tarefa. Uma dinâmica de grupo oportuniza conhecer melhor 0 candidato, identificando ou esclarecendo alguns traços da personalidade que dificilmente seriam percebidos em uma entrevista.

Dois dos métodos apresentados acima, teste e entrevista, são os mais utilizados no processo de seleção tradicional, já a dinâmica de grupo é mais utilizada no processo de seleção por competências que será apresentada mais adiante.

Nesta conjuntura, Costa (2015) diz que a seleção do candidato para uma vaga é algo crucial para a base da vida profissional do mesmo e da organização. Assim, um processo de seleção ético, bem definido e objetivo é fundamental para que o candidato se encaixe perfeitamente na vaga e com uma grande chance de crescimento. Deste modo, é necessário que toda esta ação seja baseada nos resultados e na função do cargo que está em aberto.

Para Carvalho (2010), a seleção tradicional tem uma ligação muito forte com as teorias de Frederick Winslow Taylor (1856-1915), segundo as quais existe um perfil de trabalhador para cada setor, o homem certo no lugar certo. De acordo com este autor, 
toda empresa procura um trabalhador já formado, ou seja, pela perspectiva de Taylor, trabalhadores devem ter seus setores específicos a exemplo da linha de montagem, que deve contar com trabalhadores fortes e com uma capacidade física melhor para trabalhos manuais. Consequentemente, a seleção resplandece sobre um caráter físico, a força relaciona-se à produção e tais trabalhadores devem atuar apenas nesse setor, estando restritos ao exercício daquela função. Em uma seleção tradicional, o fator de experiências técnicas no trabalho é um dos pontos mais avaliados.

Ademais, com o aprimoramento dos processos de seleção, passam a ser mais valorizadas, de forma mais criteriosa e adequada, as competências do candidato: não apenas as técnicas, mas, sim, habilidades e atitudes que se encaixam no posto a ser preenchido.

Assim, a utilização de uma nova metodologia passa a se destacar na área de $\mathrm{RH}$. Esse método é chamado de Recrutamento de Seleção por Competência e foi muito utilizado na década de 1990 e começo dos anos 2000 (COSTA, 2015).

Dado tal contexto, é importante frisar que a seleção por competência parte de um conceito genérico de processo seletivo. Esta seleção é um processo constituído por outros dois subprocessos, quais sejam, o subprocesso do recrutamento, que é um conjunto de atividades que objetivam localizar e incentivar os candidatos a disputarem vagas existentes ou a serem abertas, e o subprocesso de seleção, cuja finalidade é coletar e utilizar informações sobre os candidatos recrutados para escolher qual deles permanecerá na vaga. Os dois subprocessos dependem de uma definição do perfil de competências para o desenvolvimento das atividades (CARVALHO; PASSOS; SARAIVA 2008 apud WILWERT, 2012).

Para Avelino (2012 apud WILWERT, 2012), a seleção por competência é uma metodologia que tem como base a elaboração de um perfil das competências comportamentais exigidas pelo cargo a fim de que o recrutador ou o responsável pela seleção realize com os candidatos uma entrevista que permita encontrar o comportamento mais compatível com aquele desejável para o cargo em questão. 
Desse modo, entende-se que a seleção por competência é um processo mais objetivo e, com isso, assegura bons resultados para a empresa contratante.

A seleção por competência é fundamentada em fatos e mensuráveis por meio de habilidades, técnicas e qualidades comportamentais. É preciso analisar as limitações que envolvem os candidatos, o tempo para o preenchimento da vaga, o perfil do cargo, a estrutura da organização e a capacidade técnica do avaliador (WILWERT, 2012).

Por conseguinte, o principal objetivo da seleção por competência é procurar, junto ao candidato, vivências que comprovem que ele possui ou não uma das determinadas competências exigidas para o cargo (LEME, 2007 apud WILWERT, 2012).

Segundo Wilwert (2012), o uso da seleção por competências apresenta inúmeras vantagens para todos os envolvidos no processo de seleção, pois é feita com um porcentual de acerto muito mais alto que a tradicional, o que não previne erros durante toda essa etapa. Assim, a seleção por competência tem um maior índice de facilidade na adequação do profissional.

Ainda conforme Wilwert (2012), a seleção por competências contribui para que haja um baixo índice de rotatividade das pessoas contratadas pelas organizações, pois se trata de um processo mais seguro e com maior índice de acerto, posto que visa às atitudes comportamentais dos candidatos.

Esse tipo de seleção, segundo Costa (2015), faz uso de dinâmicas de grupo para avaliar os candidatos e suas competências para o cargo a ser preenchido. Tais dinâmicas são realizadas com o objetivo de observar e examinar os comportamentos que os candidatos teriam em um dia de trabalho, assim como lidariam com a pressão que o cargo irá exigir, como poderiam resolver alguma tarefa de maneira rápida e como poderiam adotar diferentes condutas ao abordarem os seus superior, entre outras atividades recorrentes.

Para Rabaglio (2001 apud COSTA, 2015), o grande objetivo da seleção por competência é criar um perfil de competências necessárias ao cargo, mapeando as demandas que o posto exigirá da pessoa que irá ocupá-lo. 
Entretanto, o tempo avança e a tecnologia se torna mais eficaz a cada dia que passa, revolucionando todos os setores da moderna vida corporativa, desde a produção, com maquinários de última geração e com produtividade maior, até os setores administrativos. O setor de $\mathrm{RH}$ não ficaria de fora dessas novas tendências e, no que tange ao recrutamento e à seleção, surge um novo método, o e-recrutamento, que vem ganhando adesão significativa por parte das empresas.

Segundo Peretti (2007 apud FERREIRA, 2016), a seleção online apresenta as seguintes vantagens para as empresas que a utilizam:

- Custos baixos;

- Segmentar e selecionar os candidatos por meio de pesquisa específica; e

- Definir mais concretamente os perfis dos candidatos.

Não obstante, Cappelli (2001 apud FERREIRA, 2016) revela, em um de seus estudos, que, no geral, uma organização pode demorar 43 semanas para completar um ciclo de seleção tradicional enquanto a online pode reduzi-lo para seis dias.

Outro estudo, realizado em 2013 por Pedroso (2016), mostrou que 53\% das atividades de seleção envolveram a internet e que, em 2014, passou para $61 \%$. A pesquisa demostrou, ainda, que 7 em cada 10 selecionados foram recrutados por meio de redes sociais online e que 5 em cada 10 organizações utilizaram essas redes para a procura ativa de candidatos, sendo o Linkedin a plataforma mais utilizada (PEDROSO, 2016).

Em um estudo de 2014, Pedroso (2016) afirma que os recrutadores utilizaram extensivamente as redes sociais online para verificar os perfis de seus candidatos, sendo os fatores mais avaliados: as experiências de trabalho anteriores, distinções e prêmios profissionais e características de personalidade compatíveis com a vaga Um terço dos recrutadores afirmaram ter rejeitado candidatos devidos a alguma informação, fotografia ou publicação compartilhada por meio destas redes sociais.

Apesar das vantagens desse método, Araújo e Ramos (2002 apud FERREIRA, 2016) apresentam como principais desvantagens da seleção online: 
- A exclusão de possíveis candidatos, como os que não têm acesso à internet;

- Atração de candidatos não desejáveis em número excessivo e sem as qualificações necessárias;

- A falta de transparência da informação recebida, tornando o processo de seleção e recrutamento mais impessoal e com menor contato humano;

- As dificuldades técnicas que podem dificultar o acesso à informação;

- Os currículos desatualizados;

- A discriminação ou privacidade.

Peretti (2007 apud FERREIRA, 2016) menciona que a filtragem feita pela seleção online ajuda (e muito) no processo de seleção. Contudo, para ele, a crescente utilização da internet poderá reduzir o mercado de atuação de empresas que utilizam o processo tradicional.

Carvalho e Grici (2011) dizem que outro erro comum na seleção online é o candidato camaleão ou agente camaleônico. São pessoas que se adaptam às identidades flexíveis, que mudam perante os modelos do mercado de trabalho. Em uma entrevista, essas pessoas buscam controlar as impressões que os entrevistadores têm a seu respeito, focando, principalmente, nas suas habilidades, atitudes e características, para que, desse modo, possam chegar ao seu objetivo. Geralmente, candidatos camaleônicos se preparam antes da entrevista e treinam a voz para passar uma impressão diferente do que realmente são.

Não raro, muitas pessoas fazem uso dessa técnica perversa, pois consideram que o esforço pessoal e o mérito não são suficientes para progredir em sua carreira profissional, sendo que, para eles, é de extrema importância transmitir uma imagem de competência e poder. Em geral, as entrevistas de uma seleção online são feitas por videoconferências, o que se configura em uma ótima oportunidade para o candidato camaleônico moldar sua imagem positiva, isso porque o entrevistador não terá um âmbito muito grande para avaliá-lo.

Nesse contexto, Belmonte et al. (2015) afirma que o avanço da tecnologia na área de seleção tem levado empresas e candidatos a mudarem a forma de fazer suas ofertas 
no mercado de trabalho, mesmo porque a seleção online é uma realidade, ainda que conviva com outros métodos de seleção mais tradicionais. Para os candidatos, a seleção online trouxe facilidades, como maior número de oportunidades para fazer suas escolhas profissionais, mais informações sobre as empresas e os cargos e segurança quanto ao recebimento dos currículos pelas organizações. Para as empresas, possibilitou atingir um maior número de candidatos, aumentar as possibilidades de encontrar novos talentos e padronizar a seleção, assegurando um feedback mais eficiente.

Com os métodos de seleção já apresentados, o próximo tópico desse trabalho irá apresentar uma comparação entre os três métodos.

\section{RESULTADOS E ANÁLISE}

Retomando a problemática deste estudo, a partir dos métodos de seleção já existentes, verificou-se que a seleção online é expressamente relevante para as empresas. Segundo os estudos de Pedroso (2016), observou-se que tal metodologia proporciona comodidade e facilidade às organizações por ser mais ágil e reduzir o tempo empregado em uma seleção comum. Como dito anteriormente, outra vantagem é ampliar o espectro de candidatos interessados, o que seria impossível em seleções tradicionais, a um menor custo, tornando o método ainda mais atraente para as empresas.

Segundo Coradini e Murini (2009), o processo de seleção tradicional visa chegar a uma conclusão de análise de conhecimento, como habilidades e experiências passadas de trabalho, atitudes, personalidade, entre outros fatores, relacionado à adaptação da pessoa na empresa com o gênero, porte físico, a estrutura, o endereço residencial e a idade.

No que concerne à seleção por competências, a dinâmica de grupo é uma ferramenta que pode oferecer informações riquíssimas sobre o perfil dos candidatos, principalmente, no que se refere às competências atitudinais ou comportamentais. $\mathrm{O}$ 
processo de seleção por competência é mais rápido em comparação com a seleção tradicional, mas, ainda assim, enfrenta dificuldades (CORADINI e MURINI, 2009).

Ariera e Guimarães (2005) apontam que todos os processos que compõem uma seleção servem para que os candidatos sejam submetidos às situações relacionadas com aquelas que podem se deparar no exercício do cargo. A atuação dos candidatos irá possibilitar uma observação sobre suas posturas, atitudes e habilidades, entre outros aspectos. Essas observações, somadas às demais informações obtidas por outros instrumentos que compõem o processo de seleção, permitirão a realização de um perfil sobre a atuação futura dos candidatos.

A tabela a seguir mostra aspectos positivos e negativos de cada processo de seleção (seleção tradicional, seleção por competências e seleção online):

Tabela I

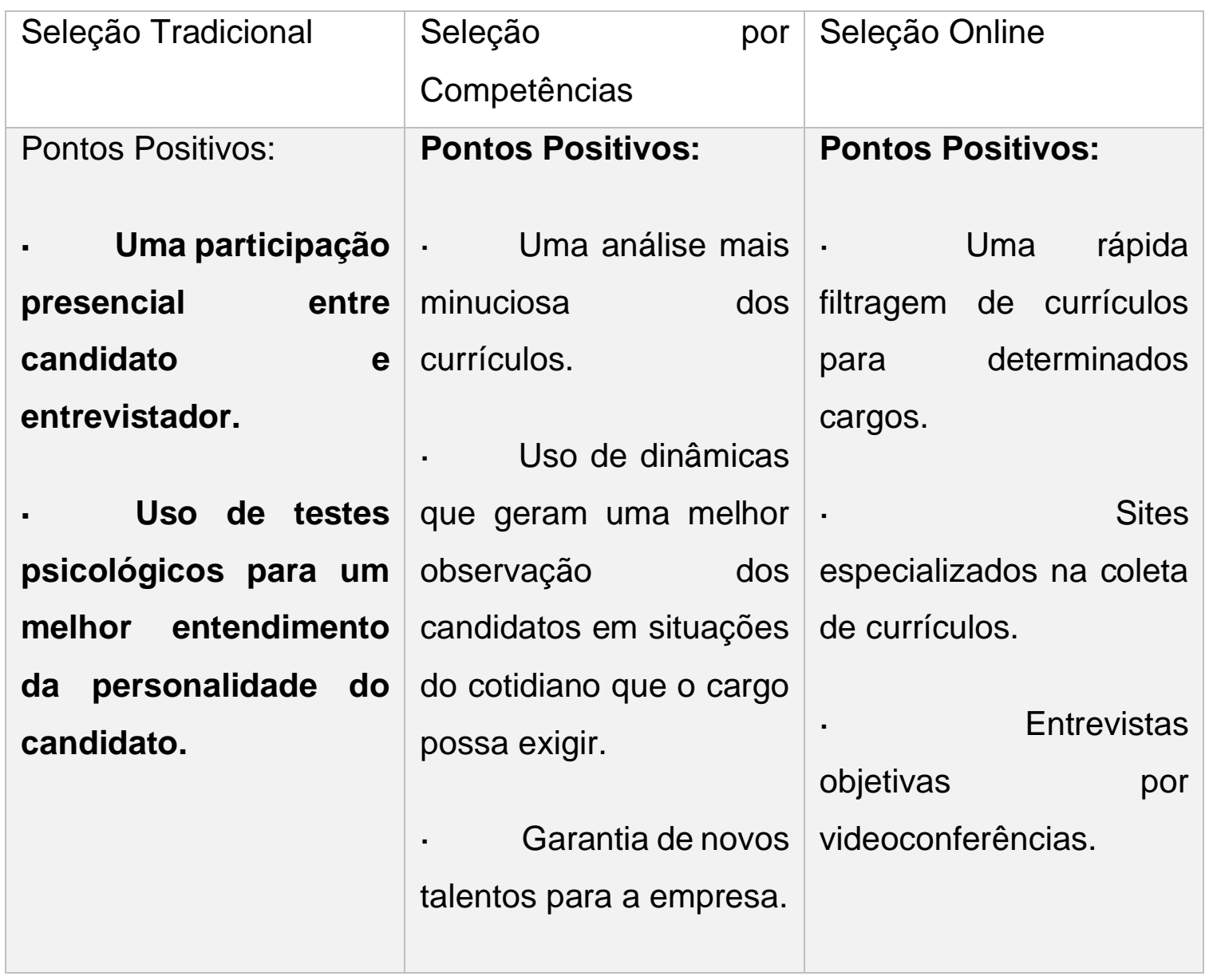




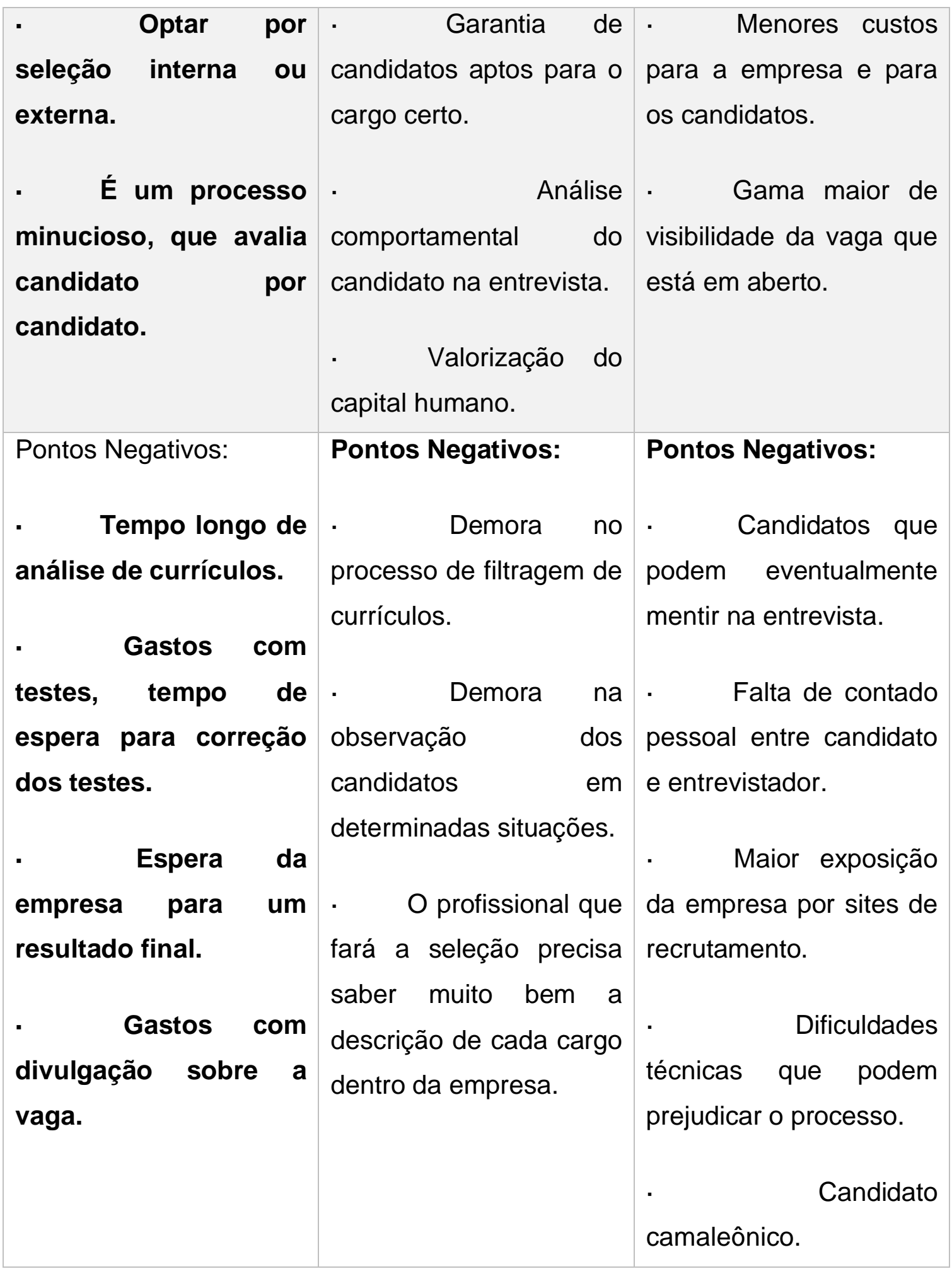

Fonte: O próprio autor.

Assim, analisando-se a tabela acima, pode-se entender que todos os processos de seleção têm seus pontos fortes e fracos. Segundo Ariera e Guimarães (2005), a 
seleção tradicional, por ser um processo mais antigo, está desatualizado como um todo, tanto na questão do tempo quanto ao custo e benefício para empresa, mas, ainda assim, é bastante utilizado por várias empresas. Entre as vantagens, pode-se destacar que, em algumas seleções, o entrevistador, sendo um psicólogo, pode fazer uso de testes psicológicos para medir e ter uma visão mais ampla da personalidade, do raciocínio logico e da inteligência, por exemplo, dos candidatos, contudo, a desvantagem está no tempo destinado para a correção desses testes e para a empresa localizar o melhor candidato.

Sobre a seleção por competências, Wilwert (2012) diz que é um processo mais atualizado. Destacam-se as dinâmicas de grupo, as quais, além de mostrar os candidatos em situações rotineiras análogas a um dia de trabalho, também são capazes de mostrar aspectos que a empresa pode explorar no caso de surgir um eventual talento. Em relação às suas desvantagens, esse processo quase se iguala ao da seleção tradicional quanto aos custos e à demora em dar o feedback para as empresas que optam por esse processo.

Para Pedroso (2016), a seleção online é o processo que mais mostra vantagens e desvantagem. Nota-se que o custo-benefício é muito mais expressivo que os outros dois métodos, haja vista a resposta rápida para os candidatos selecionados - por possibilitar, por exemplo, uma entrevista por videoconferência, a qual dispensa a locomoção até a sede da empresa -, além de proporcionar uma visibilidade maior entre os candidatos que procuram determinadas vagas. Em contrapartida, as desvantagens desse processo relacionam-se, primeiramente, à perda da interação pessoal entre o candidato e o entrevistador. A intermediação da tecnologia leva à perda de fatores importantes durante o processo de seleção, como teste de personalidade e dinâmicas para observar aspectos comportamentais em equipe, os quais podem ser explorados pelas empresas, como traços de liderança, de frustrações, entre outros aspectos que podem influenciar o trabalho daquele candidato. Em segundo lugar, como a seleção é realizada virtualmente, esse método atrai mais candidatos camaleônicos e o entrevistador pode não identificar comportamentos que denunciariam tal perfil. 
Finalizada a análise sobre os pontos fortes e fracos desses três processos de seleção, o presente trabalho encaminha-se para a sua conclusão.

\section{CONCLUSÃO}

Este trabalho teve por objetivo discutir e demonstrar, a partir de dois métodos já existentes, como a seleção online é relevante para as empresas e elucidar o impacto da tecnologia no processo de recrutamento e seleção de candidatos a um posto de trabalho.

Pedroso (2016) defende que a seleção online é um processo relativamente recente, porém, seu método está mais atualizado no contexto de captação de candidatos. De acordo com este autor, por ser um processo novo, as empresas, atualmente, têm recorrido a essa forma de seleção pelo ótimo custo e benefícios e por ter uma resposta mais rápida para o preenchimento do cargo disponível. Com a ajuda de redes sociais online, a seleção de candidatos torna-se mais criteriosa, ajudando o entrevistador e as empresas a encontrarem mais rapidamente o candidato certo para a vaga em aberto.

Esta pesquisa conclui, portanto, que o processo de seleção online está sendo utilizado por mais empresas a cada ano que passa, em razão de fatores vantajosos, como custos e benefícios, facilidade de retorno a ambas as partes (empresa e entrevistado) e redução do tempo do processo seletivo. Isto posto, mesmo contando com algumas desvantagens, a seleção online é uma realidade, está sendo praticada no mercado de trabalho e empregando novos métodos de entrevistas e análise de currículos. Esta seleção possibilita que empresa e candidato tenham uma proximidade maior, mesmo que implique resultados negativos na seleção. Logo, muitas empresas, quando querem preencher uma vaga de emprego, optam pela seleção online por ser um método mais rápido, como já foi dito anteriormente, mas, certas vezes, ignoram que as habilidades mostradas no currículo ou na entrevista podem ser apenas uma fachada para atrair a atenção do recrutador que, muitas das vezes, se detém a examinar a quantidade de habilidades e não as suas qualidades (D’ ÁVILA et al. 2010). 
Vale ressaltar que a chegada da tecnologia ao setor de Recursos Humanos, especificamente aos processos de seleção, trouxe muitas vantagens que, até então, eram difíceis de se manejar. Com a seleção online, questões como aplicação de testes psicológicos e dinâmicas de grupo passam a ser restritas a fatores de ética profissional das empresas, mas para as que optam por um processo de seleção mais rápido e fácil, a seleção online é um ótimo método.

Desse modo, a seleção online é bastante significativa para as organizações, por todos os fatores já vistos neste trabalho, além de ser um marco transformador dos métodos de seleção de pessoas, os quais estão em evolução e aperfeiçoamento contínuos. Aplicado de maneira correta e ética, tal método pode trazer novos horizontes para o setor de recursos humanos (MOURA, 2014).

Finalmente, a partir do que foi exposto acima, este estudo deixa portas abertas para futuros pesquisadores contribuírem com esta problemática de pesquisa.

\section{REFERÊNCIAS}

ALVEZ. T.R; E-RH: O Impacto Da Tecnologia Para A Gestão Competitiva De Recursos Humanos; Universidade de São Paulo; São Paulo; Brasil; 2014.

ANTUNES, G. NASCIMENTO, C. TOLEDO, M. CUNICO, E; Recrutamento e Seleção; Faculdade Sul Mineira; São Lourenço; Minas Gerais; Brasil; 2016.

ARIERIA. J.O, GUIMARAÊS. M.F; O Processo de Recrutamento e Seleção Como Uma Ferramenta De Gestão; Revista Científica Empresariais da UNIPAR, Paraná; Brasil; 2005.

BELMONT. V, PEREIRA. B. G, HOUZER. H, I. CALDEIRA, J.M. X.; Os Subprocessos De Captação E Seleção De Pessoas Sob o Impacto Das Tecnologias De Informação; Simpósio de Excelência Em Gestão e Tecnologia; Associação Educacional Dom Bosco; Rio de Janeiro; 2015. 
CARVALHO. I, M, V; Recrutamento e Seleção por Competências-Editora FGV, Rio de Janeiro, 2010.

CARVALHO. M, L. GRISI. C, L, L; Gerenciamento de Impressão na Seleção De Pessoal: Construindo Estilos De Vida Contemporâneos; Universidade Federal do Rio Grande do Sul- UFRGS, Porto Alegre, 2011.

CONFORTO. C.E, AMARAL. D.C, SILVA. A.S; Roteiro Para Revisão Bibliográfica Sistemática: Aplicação No Desenvolvimento De Produtos e Gerenciamento De Projetos; Congresso Brasileiro De Gestão De Desenvolvimento De Produto; Porto Alegre; Brasil; 2011.

CORADINI. J, R. MURINI. L, T; Recrutamento e Seleção: Como Agregar Talentos à Empresa; Universidade de Franca- UNIFRAN, Franca, São Paulo; 2009.

CORDEIRO. A.M, OLIVEIRA. G.M, RENTERÍA. J.M; Revista sistemática: uma revisão narrativa; Revista do Colégio Brasileiro de Cirurgiões; Rio de Janeiro; Brasil; 2007.

COSTA. L.C; A Tecnologia Da Informação Na Gestão Do Recrutamento E Seleção: A Importância Do Recrutamento Online; Universidade Federal Fluminense; Volta Redonda; Brasil; 2012.

D'ÁVILA. G.C, REGIS. H.P, OLIVEIRA. L.M. B; Redes Sociais e Indicações para Processos de Recrutamento e Seleção: uma Análise pela Perspectiva dos Candidatos; Revista Psicologia: Organizações e Trabalho; Brasil; 2010.

FERREIRA. O.L. M, Plataforma de e-recruitment- Novas estratégias para o recrutamento online; Universidade do Porto; Lisboa; Portugal; 2016.

MOURA. R.I. M, Recrutamento Online; Universidade Europeia; Lisboa; Portugal; 2014.

PEDROSO. R.C; Redes Sociais e Recrutamento; Universidade Católica Portuguesa; Lisboa; Portugal; 2016. 
SOUZA. M.T, SILVA. M.D, CARVALHO. R; Revisão Integrativa: O que é e Como Fazer? Universidade de São Paulo; São Paulo; Brasil; 2010.

VIEIRA. M.P. S; Impacto Das Novas Tecnologias No Recrutamento Nas Empresas Especializadas De Recrutamento e Seleção; Instituto Universitário de Lisboa; Lisboa; Portugal; 2010.

WILWERT. G, F. Recrutamento E Seleção Por Competências; Centro Universitário Leonardo da Vinci- UNIASSELVI; Santa Catarina; Brasil; 2012.

3. Projeto aprovado pelo comitê de ética com o protocolo 825/2019.

Enviado: Setembro, 2019.

Aprovado: Março, 2020. 